\title{
TEORIA DA CEGUEIRA DELIBERADA: EQUILÍBRIO EM SUA APLICABILIDADE NO ORDENAMENTO JURÍDICO PENAL BRASILEIRO
}

\section{ARTIGO ORIGINAL}

GOMES, Higor da Silva ${ }^{1}$

GOMES, Higor da Silva. Teoria da cegueira deliberada: Equilíbrio em sua aplicabilidade no ordenamento jurídico penal brasileiro. Revista Científica Multidisciplinar Núcleo do Conhecimento. Ano 05, Ed. 11, Vol. 14, pp. 39-54. Novembro de 2020. ISSN: 2448-0959, Link de acesso:

\section{RESUMO}

A teoria da cegueira deliberada é um instrumento de extrema importância a ser debatido tendo em vista a discussão quanto a possibilidade de se aplicar sanção penal a determinado agente com base em algo que ele poderia ou deveria presumir e que por se omitir, permite e facilita a ocorrência de um delito bem como se beneficia com algum tipo de vantagem pecuniária, sendo esta a problemática apresentada, trazendo o debate quanto à possibilidade e legalidade de tal teoria no âmbito do direito penal brasileiro. O presente artigo tem como objetivo apresentar a discussão acerca da aplicabilidade desta teoria utilizando-se do método lógico dedutivo e lógico indutivo, ultrapassando os campos doutrinários e partindo ao âmbito jurisprudencial não apenas o brasileiro, como aos existentes ao redor do mundo, em casos emblemáticos e de grandes repercussões, explanando ainda a origem da teoria bem como sua importação pelo nosso ordenamento jurídico. Nota-se com os resultados e conclusões a aplicação de tal teoria principalmente quanto aos crimes de lavagem de dinheiro,

${ }^{1}$ Graduado em Direito pela Pontifícia Universidade Católica do Paraná - Campus Maringá. Pós Graduado em Direito e Processo do Trabalho pelo Descomplica Pós Graduação. Pós Graduando em Ciências Penais pela Universidade Estadual de Maringá. 
apresentando o artigo exemplos contundentes e fundamentações precisas, levando em consideração o equilíbrio e proporcionalidade na análise de cada caso concreto sobre a possibilidade de se entender como dolosa a conduta de se omitir em circunstancias as quais o agente deveria se manifestar.

Palavras-chave: Teoria da Cegueira deliberada, lavagem de dinheiro, jurisprudências conflitantes, aplicabilidade nacional.

\section{INTRODUÇÃO}

A chamada "Teoria da cegueira deliberada" é o nome dado a teoria da qual considera a responsabilidade de um fato criminoso a alguém que propositalmente ignora determinada situação para não deixar de obter algum tipo de vantagem em determinado caso concreto. É uma falta de interesse em buscar um melhor conhecimento sobre um fato que aparentemente provém ou tem alguma relação com um fato criminoso, ou alguma possível ilicitude em transações, acordos, enfim, algo que levantaria certa desconfiança no "homem médio", mas que prefere "tapar os olhos" de maneira proposital, para não deixar de obter determinada vantagem. Esta teoria também é denominada de "teoria do avestruz" em razão da atitude dos avestruzes em enfiar a cabeça debaixo da terra em situações adversas (OLIVEIRA, 2019).

Ao se analisar a teoria, nota-se que não há a necessidade de que o agente tenha real conhecimento do fato, para ser responsabilizado, na verdade o que se deve comprovar é que o agente de maneira proposital ignorou a situação e mais, é necessário comprovar-se que se, tal agente não toma-se tal atitude de tapar os olhos, teria perfeitas condições de ao menos suspeitar de alguma pratica ilícita no caso concreto, utilizando-se de uma ignorância deliberada, como chamado pela doutrina (BURGEL, 2017).

O direito norte-americano utiliza-se da teoria da cegueira deliberada quando se identifica o chamado "mens rea" em tradução literal "mente culpada", ou seja, o agente está ciente das ações bem como dos resultados, mas prefere ignorar e não se 
importar. Em se tratando do direito penal brasileiro, a discussão se encontra no sentido de identificar o dolo ou a culpa, tendo em vista as raízes fincadas no "common law". A porção da doutrina brasileira que mantém favorável a aplicação da teoria em nosso território, defende a aplicabilidade abarcada pelo dolo eventual, ou seja, a consciência do possível ilícito e a decisão de se manter ignorante em uma situação em que poderia ter evitado (OLIVEIRA, 2019).

A doutrina de uma forma geral classifica determinada conduta aplicando a responsabilidade subjetiva, a quem de maneira proposital ignora fatos que provavelmente tem origem delituosa. Essa relação com a responsabilidade subjetiva se sustenta no fato de que a mesma responsabilidade que se aplica a quem conhece e está praticando o ilícito também é daquele que se faz passar por ignorante (BECK, 2011).

A maior dificuldade nestes casos, se localiza em como é analisada a suspeita, qual seriam os critérios adotados para identificar que no caso concreto o agente teria ou não como suspeitar de determinada conduta ilícita. Há que se questionar em qual momento essa análise será feita e de que forma e com quais requisitos será feita, ou seja, uma análise subjetiva do magistrado que julga a ação, baseada em suas convicções. De outro lado, tal convicção terá de advir de uma exaustiva investigação durante todo o processo até a decisão (BURGEL, 2017).

Em um caso concreto de lavagem de dinheiro, por exemplo, que aliás é grande propulsor de tal teoria, se uma pessoa ignora propositalmente em uma situação onde alguém propõe uma negociação de valor milionário e como pagamento, utiliza apenas notas de determinado valor, entregue de maneira "disfarçada" em bolsas ou malas, cabe a discussão se seria possível a condenação da pessoa que se utiliza da ignorância, caso o agente principal nesta situação fosse absolvida de qualquer acusação. É razoável pensarmos que em casos assim, o agente não responderia pela lavagem de dinheiro, ainda que pudesse ter desconfiado da conduta anterior ilícita, porém se considerarmos que o sujeito da ação anterior a esta, foi absolvido ou até mesmo nem se quer indiciado e réu em um processo, não há porque responsabilizar criminalmente o sujeito que se valeu de determinada cegueira para não deixar de 
auferir lucros advindo da negociação. Além disso, ressalta-se com profunda importância que, mesmo com a suspeita de prática criminosa anterior, inexistiria conhecimento disso, não haveria base para saber se essa suspeita se convalidava (BURGEL, 2017).

Dentre os vários requisitos que os doutrinadores estabelecem para se determinar a responsabilização ou não do agente "cego" é o fato de existir ou não informação suficiente para que ele pudesse desconfiar da conduta. Tal informação deveria estar ao alcance de qualquer pessoa para que isso seja tomado como meio de comprovação, mesmo porque ninguém tem a obrigação de saber tudo o que acontece e de maneira detalhada, ou seja, determinada informação deve ser classificada como aquela em qualquer pessoa interessada poderia ter acesso a ela. Não obstante ainda de se analisar, cabe ressaltar a questão da motivação, ou seja, deveria haver um motivo para que o agente se coloca-se em situação de ignorância, um motivo para que ele se deseja se manter "cego" no caso concreto e não uma simples ausência de curiosidade (BURGEL, 2017).

Analisando a doutrina e jurisprudência, encontra-se posicionamentos de que a responsabilidade apenas é aplicada se, além da possibilidade do agente conhecer o ilícito, ele deveria ter o dever de conhecer, ou seja, dificulta e muito a responsabilização do agente quanto ao delito pois, o fato dele dever conhecer e não só ter a possibilidade, restringe a classificação da responsabilidade.

\section{DO SURGIMENTO}

É importante que seja lembrado as raízes da desta teoria, para um melhor entendimento dos conceitos, característica dela, além de uma melhor aplicabilidade bem como análise ao aplicarmos no direito penal brasileiro.

Ao analisarmos o surgimento da teoria da cegueira deliberada, chagaremos a Inglaterra, local onde foi registrado o primeiro caso em que ela foi aplicada. É o caso Bosley V. Davies, que foi julgado em 1875. Bosley Davies foi acusado de permitir jogos ilegais em sua residência, uma pensão, porem afirmou que não tinha a mínima 
consciência de tal prática nas dependências do local. Deste modo sua defesa era pautada na ausência de conhecimento, sendo este um elemento basilar para a caracterização do delito. Porém, não foi este o entendimento do tribunal inglês que acabou por entender que o conhecimento não era necessário se presentes as circunstâncias das quais se presumiria que o acusado era conveniente com a prática dos delitos. Deste modo, tal teoria acabou por sendo adotada pelos tribunais ingleses tendo um alcance cada vez maior (ROBBINS, 1990).

Nota-se que, por mais que houve a utilização do argumento que ele não tinha consciência da ocorrência dos jogos, como forma de afastar o delito em razão da ausência de conhecimento, o tribunal entendeu que bastava as circunstancias que caracterizava uma real presunção de que o acusado era conveniente com determinadas praticas, para que o crime fosse concretizado, o que de fato ocorreu.

Como explanado, a teoria da cegueira deliberada teve sua origem na Inglaterra, local a qual foi cada vez mais utilizada. Porém seu alcance ultrapassou os limites do território inglês, chegando ao território norte-americano, local onde, a partir de 1899. Nesta época houve o julgamento do caso de Spurr V. United States. Spurr, era presidente do Commercial National Bank of Nashville, ele foi acusado de certificar um cheque de uma conta que não obtinha fundos.

Porém, pata que tal ação, conduta do presidente, caracteriza-se uma conduta ilícita, passível de ser punida com as sanções legais norte-americanas, deveria haver por parte do agente, na conduta em questão, uma intenção, ou seja, ele deveria ter o desejo, a vontade de praticar tal ato. Este foi o argumento de sua defesa para interpor recurso contra a decisão prolatada (BURGEL, 2017).

Percebe-se que, a defesa procurou pautar-se e sustentar sua fundamentação no fato de que se não houve a intenção de praticar o delito, se o agente agiu de forma a não ser real ideia do que estava fazendo em relação ao resultado final, ou seja, em ralação ao delito, não é passível de haver punição. Apesar de, em decisão primaria, os julgadores não tendo entendido desta forma, a defesa insistiu em fase recursal, na mesma tecla da falta de intenção por parte do agente em praticar um delito. 
Contudo, o tribunal acabou por permanecer na fundamentação que o réu praticou a conduta de maneira voluntaria e com voluntariedade, proposital, no sentido de que se utilizou de uma cegueira conveniente para atingir uma finalidade desejada, ou seja, aplicando de maneira clara e precisa a teoria da cegueira deliberada, pois ele sequer procurou saber se o sacador tinha de fato dinheiro em sua conta, antes de fazer a retirada (BURGEL, 2017), (RAGUÉS I VALLÈS, 2007).

Desta maneira, apesar da tentativa da defesa em se pautar na ausência de intenção do réu, o tribunal acabou por manter sua interpretação dos fatos, aplicando a teoria da cegueira deliberada no sentido de que, o agente negligenciou o seu dever de ao menos investigar se havia dinheiro para que fosse realizado o saque, ou seja, a partir do momento em que ele toma esta atitude, ele está se colocando na posição de assumir todas as consequências que poderiam advir daquela conduta.

Porém, houve uma reversão, pois os jurados não haviam sido informados de maneira contundente pelo juiz quanto a intenção do crime em questão. A corte chegou a afirmar que o júri poderia condenar o réu, com base no fato de ele ter fechado os olhos de maneira proposital, com o intuito de ser passar por ignorante na situação, se manter em uma ignorância sabida e desejada. Mesmo assim, em razão da ausência da informação necessária, houve a citada reversão na condenação do presidente do banco (RAGUÉS I VALLÈS, 2007), (ROBBINS, 1990).

\section{O SURGIMENTO NO BRASIL}

No Brasil, a teoria da cegueira deliberada começou a ser discutida no âmbito jurisprudencial e no doutrinário, com o famoso caso do "assalto" ao Banco Central de Fortaleza. Na ocasião, foram furtados uma quantia de aproximadamente 175 milhões de reais em notas de 50,00 reais (GARCIA, 2016).

Contudo, após o furto, os criminosos se dirigiram até a uma concessionária e na intenção de lavar dinheiro, adquiriram vários veículos pagos com o dinheiro em espécie, num valor de $980.000,00$ reais. Além disso, deixaram pagos mais $200.000,00$ 
reais como uma espécie de crédito, para adquirir novos veículos posteriormente (GARCIA, 2016).

Neste contexto surge a problemática da utilização ou não da teoria da cegueira deliberada pois, não seria minimamente razoável por parte do vendedor desconfiar de uma compra de tamanho valor paga com notas de apenas um valor em espécie, além disso, não seria possível desconfiar de alguém que nem ao menos adquire os veículos bem como deixa em valor creditício 200 mil reais também em espécie, em notas de apenas um valor. Estes questionamentos trazem ainda uma outra dúvida pois, tratase de um assalto que rapidamente ganhou os noticiários do país, tamanha sua magnitude e audácia, pois mais parecia cenas de um filme do que da vida real. Desta forma a divulgação, ou seja, as notícias se espalharem rapidamente, sendo assim surge uma questão no sentido de não ser razoavelmente mínimo o vendedor saber do assalto e desconfiar daquela compra de valor tão alto.

Assim, começa-se a questão de responsabilização ou não do dono da revenda de automóveis pelo crime de lavagem de dinheiro, em razão da teoria da cegueira deliberada, com base na tipicidade subjetiva, e ainda com a aplicação do dolo eventual. Verifica-se a discussão a respeito do dolo eventual pois, foi feito uma compra no valor total que ultrapassou um milhão de reais, tudo isso em notas de cinquenta reais, ou seja, seria minimamente razoável por parte do revendedor desconfiar de uma origem ilícita deste dinheiro e não realizar a negociação. Porém, ele apesar de tudo, fez o negócio, assim, segundo a teoria da cegueira deliberada, ele estaria assumindo todas as consequências de tal atitude, no momento em que ele se coloca em posição de ignorância de maneira proposital, com 0 intuito de obter a vantagem mediata naquela situação, configurando assim o dolo eventual (BURGEL, 2017).

\section{TEORIA OBJETIVA E O DOLO EVENTUAL}

No julgamento de primeira instância, sobre o caso do Banco Central, o Juiz decidiu por condenar o dono da revenda, com base na teoria da cegueira deliberada, por entender que seria minimamente razoável por parte do réu, a presunção e desconfiança da origem ilícita, e assumir as consequências daquela conduta. 
Porém, em segunda instância, o Tribunal Regional Federal reverteu a decisão, com fundamento de que as provas apresentadas pela acusação não seriam suficientes para sustentar a condenação do recorrente, pois se, no entendimento do Tribunal, se opta-se por manter tal decisão, estaria sendo aplicada a teoria objetiva no caso, o que é vedado pelo ordenamento jurídico penal brasileiro (GARCIA, 2016).

Com relação ao pagamento em espécie dos veículos, o Tribunal firmou entendimento no sentido de que tal pratica é comum na revenda de automóveis, ou seja, em razão de ser uma pratica usual neste meio negocial, seria incabível firma tese no sentido de condenar o acusado em razão de ele supostamente ter ignorado propositalmente algo de que deveria desconfiar. No entendimento do Tribunal, não seria exigível do revendedor que ele suspeitasse da origem do dinheiro, se tal provinha licitamente ou não simplesmente pelo fato de os compradores terem deixado mais de um milhão de reais em espécie, em notas iguais de um mesmo valor com o revendedor.

O Tribunal não afasta a possibilidade de se aplicar a teoria da cegueira deliberada no ordenamento jurídico penal brasileiro. Porém, firmam tese no entendimento de que tal teoria só poderia ser aplicada em casos em que o tipo penal preveja sanção na hipótese de dolo eventual, que acabou não sendo entendimento do tribunal, em razão de que, o conhecimento da origem ilícita do dinheiro é elementar típica, deste modo sendo afastada sua aplicação e decidindo pela absolvição (BECK, 2011), (BURGEL, 2017).

Observa-se que, para o Tribunal o que prevaleceu não foi a ideia de que o acusado deveria ao menos desconfiar da origem ilícita do dinheiro, ainda mais com a afirmação de que em negociações deste ramo é comum as transações em valores altos em espécie. O tribunal entendeu por afastar, neste caso, a teoria da cegueira deliberada, em função da impossibilidade de se exigir do agente uma presunção de ilicitude da origem do dinheiro, por não enxergar possibilidade de dolo eventual. Percebe-se que gera uma enorme discussão entre o mundo jurídico penal, quanto a aplicação do dolo eventual quanto a sua relação com a teoria da cegueira deliberada. Neste caso, houve a absolvição do acusado em razão das circunstâncias concretas do caso que 
afastaram a caracterização de uma possibilidade de aplicação de pena na conduta do agente.

Com este caso, a teoria da cegueira deliberada ganha grande espaço na doutrina e jurisprudências penais brasileiras, especialmente no tocante aos crimes de lavagem de dinheiro. Com a promulgação da Lei 12.683/12 que alterou a Lei 9.613/90, lei correspondente a lavagem de dinheiro, a aplicação desta teoria ganha ainda mais destaque (BURGEL, 2017).

A supracitada Lei de Lavagem traz em seu art. 1., $\S 2 . .^{\circ}$, uma alteração que tem tido uma grande repercussão nos tribunais. Tal artigo admite a possibilidade de dolo eventual no crime de lavagem, quando observamos que não existe mais a frase "que sabe serem provenientes", ou seja, para que o crime de lavagem de dinheiro seja configurado não se faz mais necessário que o agente tenha conhecimento da origem ilícita do dinheiro, basta apenas que ele utilize bens, direitos ou valores provenientes de infração penal (BURGEL, 2017), (BRASIL, 1998).

Desta maneira, A lei simplifica a aplicação do dolo eventual, pois, de uma maneira mais objetiva ela afirma que o agente será responsabilizado, independentemente de seu conhecimento pela ilicitude da origem do dinheiro, basta que ele utilize bens e direito que provenha de uma infração penal, para que seja responsabilizado penalmente por suas condutas na esfera penal.

\section{AÇÃO PENAL 470 E A DISCUSSÃO QUANTO AO DOLO EVENTUAL NA LAVAGEM DE DINHEIRO}

O mensalão, como é conhecido em todo o Brasil, ou Ação 470, explanou os questionamentos quanto a possibilidade de se validar o dolo eventual nos crimes de lavagem de dinheiro. Essa temática resultou no fato de ter que ser utilizada a teoria da cegueira deliberada como forma de basear a decisão da lavagem de dinheiro com dolo eventual (BURGEL, 2017). 
$\mathrm{Na}$ Ação Penal 470, o Supremo Tribunal Federal (STF) se baseou pela primeira vez na teoria da cegueira deliberada, para proferir uma decisão. O Ministro Celso de Mello, votou favoravelmente à condenação dos ex-deputados do PT Paulo Rocha e João Magno por lavagem de dinheiro, admitindo que "[...] a possibilidade de configuração do crime de lavagem de valores, mediante o dolo eventual, exatamente com apoio no critério denominado por alguns como 'teoria da cegueira deliberada', que deve ser usado com muita cautela" (ASSUMPÇÃO, 2017).

Ao analisarmos os votos dos ministros do Supremo Tribunal Federal, encontramos posicionamentos contrários e a favor da aplicação. A Ministra Rosa Werber, pautouse na teoria da cegueira deliberada para fundamentar seu voto, concordando com a admissão do dolo eventual neste tipo de crime. (ref netou14). Weber o dolo eventual está de maneira genérica previsto no art. 18, I, do Código Penal, não sendo necessária uma tipificação específica. A Ministra enxerga como base os fatos de o dinheiro foi entregue de uma maneira muito peculiar, pressupondo uma ocultação de forma dolosa, uma tentativa de ludibriar, além disso isso era feito de maneira consciente pelas empresas envolvidas. Além disso em nenhum momento houve qualquer tentativa de se averiguar de onde vinham (BURGEL, 2017).

Sendo assim a Ministra interpreta os fatos de maneira a deliberar que, o dinheiro, em espécie, foi entregue em malas em um hotel, sem que os beneficiários da transação tivessem ao menos se preocupados com o porquê de uma transação tão oculta, nem com a origem desses valores, eles acabam que agindo de maneira proposital a taparem os olhos e se colocarem em uma posição de ignorância proposital para se beneficiar diretamente daquela ação (BURGEL, 2017).

Desta forma nota-se que o uso do dolo eventual na lavagem de dinheiro, utilizado pela Ministra tem um cunho de social, no sentido de não se deixar em pune alguém que se valeu de uma conduta criminosa sendo beneficiário, ou seja, seria uma resposta a sociedade de que quem se beneficiou de tal ilícito por "tapar os olhos" de maneira proposital, não sairia sem sua punição, atrás do dolo eventual. Neste caso verifica-se o surgimento de uma grande problemática no sentido de tentar incluir o dolo eventual 
em relação a teoria da cegueira deliberada. É necessário que se faça uma distinção entre dolo eventual e teoria da cegueira deliberada.

No dolo eventual o agente tem ciência do que está fazendo e assume a responsabilidade quanto as consequências, apesar de desconhecê-las. A teria da cegueira deliberada se configura quando o agente deva ser responsabilizado por algo que ele poderia presumir ou deveria saber o contexto da situação fática.

Porém, é inviável não admitir o dolo eventual nos crimes de lavagem de dinheiro, pois o agente pode praticar determinadas condutas de maneira a ocultar, tendo plena ciência de que o objeto provém, muito que provavelmente, de origem ilícita e mesmo assim pratica o ato sem ao menos questionar (RAGUÉS I VALLÈS, 2007).

$\mathrm{Na}$ ação do "mensalão" em específico, existem provas suficientes para condenar os réus que se beneficiaram de maneira dolosa, pois ao se analisar o caso, qualquer cidadão "médio" recusaria o recebimento de valor em dinheiro tão grande em espécie e nem ao menos desconfiaria da licitude da moeda e o porquê de estar sendo feita uma transação naqueles moldes (ROBBINS, 1990).

Esta figura do homem "médio" é a que prevalece com o entendimento da Ministra Rosa Weber, pois, ela aponta o que hipoteticamente seria de conhecimento dos agentes naquela situação, o que de certa forma afeta a segurança jurídica das decisões. A Ministra relaciona o dolo do crime de lavagem de dinheiro, não a vontade de lavar, mas sim a de receber o dinheiro (BURGEL, 2017).

Doutrinadores afirma que o dolo, nos crimes de lavagem de dinheiro está na finalidade de ludibriar o manuseio dos bens ilícitos, com origem de um crime (CALLEGARI, 2008). Por este entendimento, o agente primeiro deve ter ciência de que o objetivo provém de uma prática ilícita e ainda, ter como objetivo dissimular os bens. Rosa Weber limita a responsabilidade aos destinatários finais e não dos subordinados (BURGEL, 2017). Analisando esta questão específica, não há como discordar do entendimento da Ministra, pois, mesmos que os subordinados suspeitassem da origem delituosa, eles não poderiam ter controle sobre as circunstâncias. 
Outro posicionamento importante de ser apresentado, em se tratando dessa discussão do dolo eventual em relação aos crimes de lavagem de dinheiro foi o da Ministra Carmem Lúcia, que admita a configuração do dolo eventual. Porém, ela afirma a necessidade de que quando é aceito o resultado da lavagem de dinheiro, o agente sabia, tinha perfeita ciência da ilicitude da ação antecedente, ou seja, ele sabia da ocorrência do crime antecedente (BRASIL, 2013).

O Ministro Luis Fux coloca uma condição para que seja admitido o reconhecimento da figura do dolo eventual neste caso concreto. Segundo seu entendimento, tal condição se relaciona não a proveniência do dinheiro, se lícita ou não, mas fundamentou seu voto com base naquilo em que o agente deveria saber, ou seja, que o agente sabia ou deveria saber ter origem crime (BRASIL, 2013).

Por outro lado, o Ministro Dias Toffoli fundamentou seu voto de maneira diversa daquela de seus colegas, não admitindo a possibilidade de condenação por dolo eventual nos crimes de lavagem de dinheiro, e pela não aplicação da teoria da cegueira deliberada. Em suas palavras o Ministro relata que:

[...] Então, se alguém movimentasse um dinheiro de cuja origem desconfiasse (dinheiro vivo, em espécie, em mala, em pacote, em carroforte etc.), como havia a necessidade de tipos específicos como antecedentes, seria cabível aplicar a ele o dolo eventual? Eu penso que não. Eu penso que não que não seria possível aplicar-se o dolo eventual, ou seja, aquele conceito do homem médio, aquele velho conceito do bonus pater familiae. Não era todo ou qualquer crime que dava ensejo à lavagem. Se não era todo ou qualquer crime, quem manipulasse certos valores, mesmo desconfiando que a sua origem não fosse lícita, mesmo desconfiando que aquilo não era da normalidade do homem médio, ele saberia se aquilo era proveniente de um crime contra a Administração Pública, contra o sistema financeiro ou proveniente de furto? Em casos como esse, seria cabível aplicar o dolo eventual? Até a nova legislação, eu entendo que não (...). Sim, mas como haver cegueira deliberada sobre tipo que a pessoa desconhece? É impossível! [...] (Ministro Joaquim Barbosa: 2013. p. 3273-3274)

Percebe-se que, no entendimento do Ministro, ao afastar a teoria, os agentes não tinham conhecimentos dos elementos necessários para configurar crime, ou seja, não 
tinham consciência da procedência ilícita do dinheiro, e assim, não sendo possível a condenação (BURGEL, 2017).

O Ministro Gilmar Mendes se manifestou da seguinte maneira:

[...] na minha compreensão, as condutas de ocultar e dissimular exigem o dolo direto, pois afiguram-me inconciliáveis com a mera aceitação de produzir o resultado. Quem oculta ou dissimula o faz querendo o resultado, não apenas admitindo sua ocorrência. [...] (Ministro Gilmar Mendes: 2013. p. 5717-5718)

Recentemente, esta teoria foi aplicada na operação "Lava Jato", podendo citar por exemplo o então Juiz Federal Sérgio Moro que se referia a tal teoria para fundamentar alguma de suas decisões na condenação de acusados por lavagem de dinheiro, utilizando a figura do dolo eventual. O então Juiz que a aplicação de tal teoria é bem utilizada pelo Supremo Tribunal Espanhol que possui corte jurídica parecida com a brasileira, onde afirma:

[...] são aqui pertinentes as construções do Direito anglosaxão para o crime de lavagem de dinheiro em torno da "cegueira deliberada" ou "willful blindness" e que é equiparável ao dolo eventual da tradição do Direito Continental europeu. Escrevi sobre o tema em obra dogmática. Em síntese, aquele que realiza condutas típicas à lavagem, de ocultação ou dissimulação, não elide o agir doloso e a sua responsabilidade criminal se escolhe permanecer ignorante quando a natureza dos bens, direitos ou valores envolvidos na transação, quando tinha condições de aprofundar o seu conhecimento sobre os fatos [...] (ASSUMPÇÃO, 2017).

Nota-se que apesar de divergências, a teoria é aplicada no direito penal brasileiro, principalmente no que tange aos crimes de lavagem de dinheiro. Porém, importa salientar a possibilidade de aplicação de tal teoria em outros delitos previstos no Código Penal como por exemplo os delitos de receptação qualificada, contágio de moléstia venérea e de entrega de filho a pessoa inidônea expressamente preveem a possibilidade de condenação por dolo eventual, ao se utilizarem da locução "deva saber" (ASSUMPÇÃO, 2017).

Dada as informações, casos, explanado acima, bem como a análise dos votos e posicionamento de alguns Ministros, percebemos os posicionamentos divergentes em 
relação a aplicação da teoria da cegueira deliberada nos crimes de lavagem de dinheiro, bem como a aplicação ou não do dolo eventual, no âmbito desta teoria. Fazse necessária uma cautelosa análise de cada caso concreto, suas circunstâncias e características, para que o uso de tal teoria não fira os direitos de cada acusado.

\section{ENTENDIMENTO CRÍTICO A RESPEITO DA APLICABILIDADE}

Como já exposto acima, a teoria da cegueira deliberada, traz à tona a questão de se responsabilizar penalmente o agente que se vale de uma cegueira proposital, ignorando tal situação. Além disso, discute-se a possibilidade de aplicação do dolo eventual na análise dos fatos para a aplicação da pena.

Analisando a aplicação desta teoria em outros países, os Estados Unidos da América por exemplo aplicam-na na possibilidade de haver prova de que o agente tenha conhecimento da alta probabilidade de que os bens, valores, sejam oriundos de ação ilícita, tendo o agente agindo de forma a ignorar tal situação (BECK, 2011). É possível encontrarmos algumas lacunas em tal entendimento, ou seja, alguns aspectos que não trazem estabilidade para o entendimento, como por exemplo a questão da probabilidade, pois isso é muito subjetivo, o que seria considerado como possível de se conhecer ou não; quem seria capaz de obter determinado conhecimento, e quem não; quem determinaria que o agente poderia e deveria conhecer o fato e de que forma essa opinião seria formada e com quais argumentos (BURGEL, 2017).

Além disso, o que seria necessariamente este conhecimento, como caracterizar que tal conhecimento seria suficiente ou não para chegar ao entendimento de que o agente com base em tal conhecimento poderia não ter ignorado tal situação e que por tal razão deve ser condenado pela prática de um crime. Essa dúvida quanto à possibilidade de o agente ter ou não conhecimento pode gerar várias ramificações de entendimento, como a de equiparação de tal teoria com os crimes culposos. Porém, errado está tal comparação pois, o problema de tal teoria não é a existência ou não de dolo, mas sim dar uma estabilidade e objetividade nos fundamentos para que ele seja configurado (Ação Penal 470, Página 17). 
Com a discussão doutrinárias, surge a ideia de que para a aplicação desta teoria é necessário que o agente conheça o ilícito e que também tenha o dever de conhecêlo, é o que sustenta parte da doutrina. Assim, o agente que que deveria ter conhecimento da prática do crime, e se coloca em posição de ignorância de maneira proposital, acaba que por omitir-se de seu dever. Desta forma, entende-se que a teoria da cegueira deliberada aplicar-se-ia apenas na existência da figura do garante, nos casos de omissão impropria onde o agente tinha o dever de agir e assim não o fez, e que esse dever partiria do conhecimento que o agente também deveria ter (BURGEL, 2017).

A partir de tal omissão por parte do agente o resultado do crime se consumou, ou seja, não exerceu seu dever de agir de maneira diversa àquela de simplesmente ignorar toda a situação, devendo assim responder pelo crime como se o tivesse praticado. $O$ Código Penal no art. $13, \S 2^{\circ}$, prevê o dever de agir do agente, na alínea "b", tem-se uma obrigação de cuidado, ou seja, se o ordenamento jurídico já prevê responsabilidade aos agentes que estão em posição de garante e acabam que se omitindo, e entendo que para que o agente, que não agiu, seja responsabilizado seria necessário o dever de conhecer o delito, ou seja, seria necessário que ele fosse garante, talvez a aplicação da teoria da cegueira deliberada seja apenas uma redundância daquilo que já está previsto no Código Penal Brasileiro (BURGEL, 2017).

Portanto, com base em todo os contexto acerca da teoria da cegueira deliberada, é necessário que na aplicação da mesma seja tomada muita cautela, muito cuidado para evitar injustos penais, condenações baseadas em convicções já superadas pelo direito penal, como é o caso da teoria objetiva pois, ao se condenar o agente com base unicamente em um conhecimento que ele deveria ter, nos leva ao princípio do "versari in re ilícita", ou seja, aplicação de algo já superado. Além disso é necessário lembrarmos da já existência de previsão legal para casos de omissão impropria no nosso ordenamento jurídico (BURGEL, 2017).

Como tudo no direito, há de se haver um equilíbrio nos casos onde se verificar necessária a aplicação da teoria. Não há de se entender que tal deve ser abolida do ordenamento jurídico penal, pois, como já explanado, há situações onde facilmente 
se prova que o agente se valeu de uma cegueira de maneira proposital. 0 ordenamento jurídico não pode tomar a mesma atitude do agente e simplesmente "tapar os olhos" para um caso onde uma pessoa se coloca em posição de ignorância em um contexto delituoso apenas para não deixar de aferir algum benefício, e assim não puni-lo pelo fato do mesmo, em sua defesa, alegar "que não sabia".

Por outro lado, não se pode utilizar a teoria para simplesmente punir réus de maneira demasiada, sem o mínimo de fundamentação valida e contundente, apenas para saciar os anseios populares de punição, principalmente em casos grandes e de grande conhecimento popular. Trata-se de um instrumento que se usado de maneira equivocada, provoca uma grande instabilidade e insegurança jurídica, mas veja, se utilizado de maneira equivocada, e não apenas o fato de utilizá-lo, como tudo no direito penal brasileiro.

\section{CONCLUSÃO}

A teoria da cegueira deliberada, surgiu com o intuito de responsabilizar criminalmente todos os agentes que, em meio a um caso concreto, se coloquem em uma posição de ignorância proposital, ou seja, "tapam" os olhos e nada fazem em meio a uma situação clara de ilícito penal.

Com origens na Inglaterra e influente aplicabilidade nos Estados Unidos da América em casos emblemáticos, onde os acusados se valeram de uma ignorância proposital para não deixar de obter determinada vantagem patrimonial. Percebe-se que os julgadores buscam não deixar em punir agentes que poderiam não ter se envolvidos em determinadas situações, dada a possibilidade de se presumir que aquilo era ilícito, mas que preferem se omitirem.

No Brasil esta teoria surgiu no caso do furto ao Banco Central de Fortaleza, conhecido em todo Brasil pela grande quantidade de dinheiro que foi furtada e pela maneira como isso aconteceu. Como já explanado, os agentes ativos do delito, após o crime, se dirigiram até uma revendedora de veículos e ali fizeram uma compra de um valor milionário em notas de 50,00 reais. Surge então a acusação contra o vendedor de 
lavagem de dinheiro, configurando seu dolo no fundamento de que, era mais do que presumível que todo aquele dinheiro tinha uma origem ilícita, e mesmo assim ele se sujeitou a tal conduta, por tal fato deveria responder pelo crime, segundo a supracitada teoria.

Outro caso muito emblemático no Brasil é a da Ação 470, do "mensalão" onde alguns dos Ministros do Supremo Tribunal Federal entenderam pela aplicação da teoria da cegueira deliberada, em razão da ignorância proposital em que se colocaram, em uma situação onde seria mais do que possível, para o homem médio, presumir que tal dinheiro provinha de algo ilícito.

Dado os casos emblemáticos e as características, passamos ao entendimento crítico e aplicabilidade de tal teoria no ordenamento jurídico penal brasileiro, chegando a conclusão de que, para a aplicabilidade da mesma, é necessário que o julgador tenha extrema cautela, por exemplo com a questão do subjetivismo das ideias de o que seria configurado como presumível, qual o limite entre o que o agente poderia saber ou não, ainda, aprofundar-se na ideia sobre o que o agente não só poderia como deveria ter conhecimento.

Ressalta-se ainda o fato de o Código Penal já dispor sobre a punibilidade daquele que deveria agir e não age, que é o caso dos crimes omissivos impróprios, pois, se o agente deveria ter conhecimento de tal fato, ele estava em uma posição de garante. Além disso, aponta-se o fato de não equipararmos a teoria com os crimes culposos, tendo em vista que na aplicabilidade daquela, há a necessidade de dolo por parte do agente, sobretudo o eventual.

Por outro lado, não se pode ignorar o fato de que em muitos dos casos os agentes se fazem sim se passar por ignorantes, se colocam nesta situação de maneira proposital a fim de obter alguma vantagem, e devem responder por isso. Não se pode simplesmente não punir alguém que se envolve em uma situação criminosa, mesmo que de maneira omissiva, e que de maneira clara e precisa se identificar tal omissão proposital, o que o inclui como sujeito ativo. 
Portanto, com todas as análises e críticas do presente artigo, se buscou chegar à ideia do balanceamento de opiniões, ou seja, não extinguir a teoria da cegueira deliberada e nem a usar de maneira irresponsável. O ordenamento jurídico brasileiro deve ser respeitado e a segurança jurídica não deve ser abalada, nem por ausência de punição em casos concretos claramente delituosos e nem por excesso ou falta de fundamentação em casos que carecem destas para serem concluídos e punidos.

\section{REFERÊNCIAS}

ASSUMPÇÃO, B. A. A, Pedro. A teoria da cegueira deliberada e a equiparação ao dolo eventual. Escola da Magistratura do Estado do Rio de Janeiro. 2017.

BECK, Francis. A doutrina da cegueira delibera e a sua (in)aplicabilidade ao crime de lavagem de dinheiro. Revista de Estudos Criminais. n. 41, abr./jun., 2011. p. 47.

BRASIL. Supremo Tribunal Federal. Ação Penal 470. Ministro Joaquim Barbosa: 2013.

p.32733274.Disponívelem:http://www.stf.jus.br/arquivo/cms/noticianoticiastf/anexo/re latoriomensalao.pdf. Acesso em: set. 2020.

BRASIL. Supremo Tribunal Federal. Ação Penal 470. Ministro Joaquim Barbosa: 2013.

p.57175718.Disponívelem:http://www.stf.jus.br/arquivo/cms/noticianoticiastf/anexo/re latoriomensalao.pdf. Acesso em: set. 2020.

BRASIL. Supremo Tribunal Federal. Ação Penal 470. Ministro Joaquim Barbosa: 2013.

p.2082.Disponívelem:http://www.stf.jus.br/arquivo/cms/noticianoticiastf/anexo/relatori omensalao.pdf. Acesso em: set. 2020.

BRASIL. Supremo Tribunal Federal. Ação Penal 470. Ministro Joaquim Barbosa: 2013.

p.3188.Disponívelem:http://www.stf.jus.br/arquivo/cms/noticianoticiastf/anexo/relatori omensalao.pdf. Acesso em: set. 2020. 
BURGEL, Letícia. A teoria da cegueira deliberada na ação penal 470 . Revista Brasileira de Ciências Criminais. vol. 129/2017, p. 479 - 505, 2017.

CALLEGARI, André Luis. Lavagem de dinheiro: aspectos penais da Lei no 9.613/98. 2. ed. Porto Alegre: Livraria do Advogado Editora, 2008. p. 111.

GARCIA, Simone. Teoria da cegueira deliberada e seus desdobramentos no Direito Penal Comparado e Brasileiro. JusBrasil. Publicado em: 01/2016. Disponível em: https://jus.com.br/artigos/45718/teoria-da-cegueira-deliberada-e-seusdesdobramentos-no-direito-penal-comparado-e-brasileiro. Acesso em: set. 2020.

OLIVEIRA, Rososki Suzana. Aplicações da teoria da cegueira deliberada no direito penal brasileiros. Canal Ciências Criminais. Publicado em: 26/01/2019. Disponível em: https://canalcienciascriminais.com.br/aplicacao-teoria-da-cegueira-deliberada/. Acesso em: set. 2020.

RAGUÉS I VALLĖS, Ramon. La ignorancia deliberada en Derecho Penal. Barcelona. Atelier, 2007. p. 65.

ROBBINS, Ira P. The Ostrich Instruction: Deliberate Ignorance as a Criminal Mens Rea. JCLC, 81 (1990). p. 196.

Enviado: Novembro, 2020.

Aprovado: Npvembro, 2020. 